\title{
ANALISIS PENGARUH TINGKAT AKURASI KLASIFIKASI CITRA WAYANG DENGAN ALGORITMA CONVOLUTIONAL NEURAL NETWORK
}

\author{
Muhammad Resa Arif Yudianto, Kusrini, Hanif Al Fatta \\ Magister Teknik Informatika, Fakultas Ilmu Komputer, Universitas Amikom Yogyakarta \\ Jl. Ring Road Utara, Kabupaten Sleman, Daerah Istimewa Yogyakarta \\ muhammadresa0203estudents.amikom.ac.id, kusrinieamikom.ac.id, hanif.a@amikom.ac.id
}

\begin{abstract}
The development of technology is inversely proportional to cultural preservation in Indonesia. One of Indonesia's cultures which creates character through the advice and stories is a puppet. But this culture shows less because the devotees have decreased. This makes young people not knowing the names of puppet figures. The introduction of digital images of puppets through the system is very necessary to introduce to the generation of millennial children, bearing in mind that at this time people are familiar with the technology. This recognition is through the image classification of puppet figures with classification algorithms that have been trained previously with puppet images that have been labeled before. To recognize various puppet figures well, a good model is needed. The quality of the model can be measured by the accuracy, precision, and recall variables in the model testing. Several factors influence the formation of the model, including the rise of the dataset, number of iterations (epoch) in learning, and of course the treatment of data before it is used in the process of forming the model. This study used 400 datasets which are divided into 4 classes which will be trained using CNN (Convolutional Neural Network) algorithm to produce a model. Based on the results of experiments obtained the best accuracy of $97 \%, 93 \%$ precision, and $87 \%$ recall by applying a combination of augmentation, changing the image to grayscale in preprocessing stage, the use of 80:20 dataset ratio and 100 epoch is a very significant effect in increasing accuracy.
\end{abstract}

Keywords - Classification, Punakawan Puppets, CNN, Image Processing.

\begin{abstract}
Semakin berkembangnya teknologi berbanding terbalik dengan perkembangan pelestarian kebudayaan di Indonesia. Salah satu kebudayaan Indonesia yang bermanfaat membentuk karakter melalui nasihat dan cerita di dalamnya adalah wayang. Akan tetapi kebudayaan ini semakin jarang terlihat pertunjukkannya dikarenakan peminatnya telah berkurang. Hal tersebut mengakibatkan anakanak muda tidak mengenal nama tokoh-tokoh pewayangan. Pengenalan citra digital tokoh pewayangan melalui sistem sangat diperlukan untuk mengenalkan kepada generasi anak milenial, mengingat saat ini masyarakat telah terbiasa dengan teknologi. Proses pengenalan ini melalui proses klasifikasi citra tokoh wayang dengan algoritma klasifikasi yang telah dilatih sebelumnya dengan data-data citra wayang yang telah diberi label sebelumnya. Untuk dapat mengenali berbagai tokoh wayang dengan baik dibutuhkan model yang baik. Kualitas model dapat diukur dengan variabel akurasi, presisi dan recall pada proses pengujian model. Terdapat beberapa faktor yang mempengaruhi pembentukan model, diantaranya adalah raiso pembagian dataset, jumlah perulangan (epoch) dalam pembelajaran dan tentunya perlakuan terhadap data sebelum digunakan dalam proses pembentukan model. Pada penelitian ini digunakan dataset sebanyak 400 data yang terbagi ke dalam 4 kelas yang akan dilatih menggunakan algoritma CNN (Convolutional Neural Network) untuk menghasilkan model. Berdasarkan hasil percobaan yang dilakukan didapatkan akurasi terbaik sebesar $97 \%$, presisi $93 \%$ dan recall sebesar 87\% dengan menerapkan kombinasi augmentation, mengubah citra menjadi grayscale pada tahap preproccessing, penggunaan rasio dataset 80:20 dan epoch sebesar 100 sangat berpengaruh signifikan dalam meningkatkan nilai akurasi.
\end{abstract}

Kata kunci - Klasifikasi, Wayang Punakawan, CNN, Pengolahan Citra.

\section{PENDAHULUAN}

Salah satu kebudayaan di Indonesia yang telah dikenal oleh masyarakat Jawa sejak kurang lebih 1500 tahun yang lalu adalah kesenian wayang. Menurut [1], pada mulanya wayang ini merupakan kebudayaan yang dimainkan dengan bayang-bayang dan dikenalkan oleh orang-orang hindu terhadap kebudayaan Jawa dan digunakan sebagai pemujaan terhadap roh leluhur. Wayang dibedakan menjadi 2 jenis yaitu wayang orang yang diperankan langsung oleh orang dan wayang boneka yang digerakkan oleh seorang dalang. Salah satu jenis wayang boneka adalah wayang kulit. Wayang kulit terbuat dari boneka kayu dan kulit sebagai pakaiannya [2].

Menurut para ahli selain sebagai pertunjukan dan hiburan, wayang juga berguna untuk membentuk watak dan karakter seseorang [3]. Dalam penelitiannya [4], salah satu contoh tokoh pewayangan yang banyak dikenal adalah punakawan yang terdiri dari Semar dan 
ketiga anaknya yaitu Gareng, Petruk dan Bagong. Tokoh-tokoh ini memiliki karakter yang ceria, lucu dan khas dengan pesan moral yang selalu dibawakan dalam setiap pertunjukkan wayang. Akan tetapi kebudayaan wayang yang dahulunya berkembang dengan jumlah yang banyak, saat ini tinggal berjumlah 25 yang masih ada di masyarakat. Hal tersebut terjadi karena lemahnya ketiga faktor berikut, yaitu faktor pelaku yang berkarya, kelompok masyarakat yang mencintai budaya wayang dan dukungan dari pemerintah [5]. Kebudayaan ini lama kelamaan akan mengalami kemusnahan dan tidak sedikit dari generasi berikutnya yang tidak mengenal tokoh-tokoh pewayangan disebabkan karena tidak adanya pelaku yang memainkan pertunjukan wayang di masyarakat.

Pengenalan citra digital tokoh-tokoh pewayangan oleh sistem saat ini sangat diperlukan untuk mengenalkan kepada generasi anak milenial, mengingat semakin jarangnya diadakan pertunjukan wayang saat ini dan perkembangan teknologi yang semakin pesat. Proses pengenalan ini melalui proses klasifikasi citra tokoh wayang dengan algoritma klasifikasi yang telah dilatih sebelumnya dengan data-data citra wayang yang telah diberi keterangan/label sebelumnya.

Penelitian sebelumnya oleh Sandy untuk mendeteksi dan mengklasifikasikan wayang menurut bentuknya menggunakan algoritma $\mathrm{KNN}$ ( $K$-Nearest Neighbor) dan GLCM (Gray Level Co-occurrence Matrix). Data citra diperoleh melalui proses pengambilan gambar menggunakan kamera. Hasil penelitian menunjukkan tingkat akurasi dari keseluruhan citra rata-rata akurasinya adalah sebesar $77,5 \%$ [6]. Dalam penelitiannya [7] mengeksplorasi dan mencari metode klasifikasi gambar dengan tingkat pembelajaran yang paling tinggi antara algoritma SVM (Support Vector Machine), CNN (Convolutional Neural Network) dan ANN (Artifical Neural Network). Dari ketiga algoritma yang diujikan SVM berada pada urutan terakhir dengan nilai akurasi $98 \%$ dan algoritma CNN dan ANN memiliki tingkat akurasi yang sama tingginya yaitu sebesar $99,5 \%$.

Penelitian terdahulu oleh Cheng ingin membandingkan algoritma CNN dengan parameter tambahan ERACNN dibandingkan dengan algoritma RBF-SVM, Linear-SVM dan KNN. Dalam penelitian tersebut objek yang digunakan sebagai dataset adalah emosional seseorang dengan sinyal EEG (electroencephalogram). Dari hasil percobaan didapatkan bahwa algoritma CNN mengungguli dari ketiga algoritma yang lain dengan tingkat akurasi sebesar $83,45 \%$ pada 2 kategori emosional (optimis dan pesimis) dan $68,8 \%$ untuk 3 kategori emosional (optimis, kalem dan pesimis). Minimnya dataset sangat mempengaruhi hasil akurasi yang didapatkan [8].

Dari beberapa uraian tersebut, maka peneliti mengambil judul penelitian "Analisis Pengaruh Tingkat Akurasi Klasifikasi Citra Wayang dengan Algoritma Convolutional Neural Network". Hasil dari penelitian ini diharapkan dapat melakukan klasifikasi citra wayang dengan baik melalui beberapa skenario percobaan terhadap pengaruh parameter dan perlakuan pada proses training menggunakan algoritma Convolutional Neural Network untuk mendapatkan tingkat akurasi yang tinggi.

\section{A. Pengolahan Citra Digital}

Proses pengolahan data teks berbeda dengan pengolahan citra. Dalam pengolahan citra ini dilakukan dengan beberapa teknik untuk memanipulasi citra agar dapat diketahui perbedaan atau ciri khas yang membedakan antara citra yang satu dengan citra yang lain. Pengolahan citra adalah proses memanipulasi citra dengan mesin komputer dengan maksud agar kualitas citra tersebut menjadi lebih baik [9]. Terdapat satu hal yang penting dalam konsep pengolahan citra yaitu mengekstrak informasi dari citra tersebut, sebagai contoh seperti pengenalan berdasarkan bentuknya. Salah satu metode pengolahan citra yaitu Edge detection, yaitu pemrosesan citra terhadap bidang feature detection dan feature extraction. Edge merupakan batas-batas dalam sebuah objek yang digunakan untuk mendeteksi dan mengidentifikasi tepi dalam citra digital [10].

\section{B. Klasifikasi}

Dalam bukunya [11] disebutkan bahwa klasifikasi merupakan langkah atau cara dalam upaya membentuk suatu model atau fungsi yang digunakan dalam menjelaskan atau membedakan konsep kelas data. Dengan melakukan proses ini suatu objek dapat dikenali dan dikelompokkan berdasarkan kelasnya dengan cara memperkirakan berdasarkan hasil dari model yang telah dibentuk. Klasifikasi dokumen adalah bagian proses yang penting dalam bidang sistem informasi, khusunya untuk pengetahuan bisnis. Proses klasifikasi terbagi menjadi dua tahapan yaitu pelatihan (learning) yaitu tahap pembelajaran terhadap suata data yang telah diketahui kelasnya dan pengujian (testing) yaitu melakukan evaluasi tingkat kinerja dari model hasil dari tahap learning dengan data baru yang disebut data uji. Keluaran dari tahap ini berupa tingkat keakuratan suatu model dalam memprediksi data yang belum diketahui kelasnya yaitu dengan data uji [12].

Proses klasifikasi sangat erat hubungannya dengan teknik atau algoritma yang dapat belajar dan mengelompokkan data ke dalam kelas-kelasnya. Beberapa algoritma yang dapat digunakan dalam proses klasifikasi diantaranya adalah Naive Bayes Classifier, Decision Tree, Rule Based Classifier dan Jaringan Saraf Tiruan atau lebih dikenal Neural Network. Masingmasing algoritma memiliki cara kerja yang berbedabeda dalam proses klasifikasi data, selain itu setiap algoritma juga memiliki kelebihan dan kekurangan masing-masing dalam melakukan klasifikasi pada banyak kasus [12]. 


\section{Convolutional Neural Network}

Convolutional Neural Network (CNN) adalah algoritma klasifikasi hasil dari pengembangan Multilayer Perceptron (MLP) yang dibangun untuk memproses data dua dimensi. Karena kedalaman jaringan yang tinggi dan banyak diterapkan pada data gambar/citra sehingga CNN termasuk dalam dari Deep Neural Network. Pada CNN, data yang dipropagasikan pada jaringan adalah data dua dimensi, sehingga operasi linear dan parameter bobot pada CNN berbeda. Pada CNN operasi linier menggunakan operasi konvolusi, sedangkan bobot tidak lagi satu dimensi saja, namun berbentuk empat dimensi yang merupakan kumpulan kernel konvolusi [13].

\section{Arsitektur Convolutional Neural Network}

Secara garis besar bagian-bagian yang terdapat pada arsitektur algoritma Convolutional Neural Network dapat dilihat pada gambar 1. :

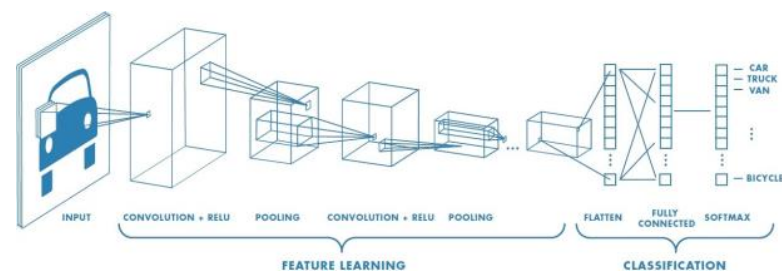

Gambar 1. Arsitektur Convolutional Neural Network

\section{Convolutional Layer}

Convolutional layer adalah sebuah proses dimana citra dimanipulasi dengan menggunakan eksternal mask atau subwindows untuk menghasilkan citra yang baru. Proses ini adalah mereduksi dimensi dari citra dengan operasi convolutional untuk mengekstrak fitur-fitur penting dari citra seperti deteksi ciri/edge, warna, orientasi gradien, dll melalui proses encoding. Secara matematis konvolusi adalah jumlah total dari hasil kali antara setiap elemen yang bersesuaian (memiliki posisi koordinat yang sama) dalam dua matriks atau dua vektor, seperti yang ditunjukkan Gambar 2 [14].

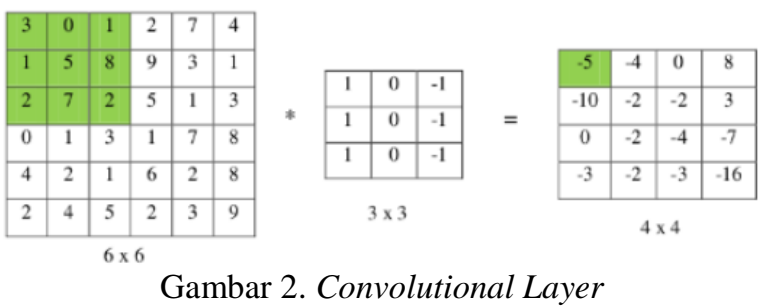

\section{Pooling Layer}

Pada bagian pooling layer ini terjadi proses mereduksi ukuran sebuah data citra. Dalam pengolahan citra, pooling juga bertujuan untuk meningkatkan invariansi posisi dari fitur serta mempercepat komputasi dan mengontrol terjadinya overfitting. Layer ini juga bertugas dalam mengurangi dimensi. Dalam prosesnya, membutuhkan kemampuan komputasi yang tinggi dalam memproses data. Layer ini sangat berguna untuk mengekstrak fiturfitur penting dengan berbagai variasi posisi citra dan rotasi sehingga proses training nantinya akan efektif seperti Gambar 3 berikut ini.

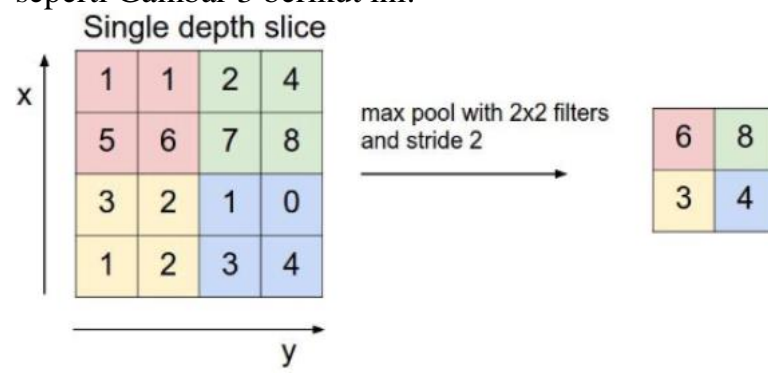

Gambar 3. Proses pada Pooling Layer

\section{Fully Connected Layer}

Setiap neuron pada convolutional layer perlu ditransformasi menjadi data satu dimensi terlebih dahulu sebelum dapat dimasukkan ke dalam sebuah fully connected layer. Feature map yang dihasilkan dari proses feature extraction dengan convolutional dan pooling layer masih berbentuk multidimensional array, sehingga harus dilakukan flatten atau reshape feature map menjadi sebuah vector agar bisa digunakan sebagai masukan dari fully connected layer. Vector hasil proses flatten akan diumpankan dan diproses dengan feed forward neural network dan backpropagation untuk setiap proses pelatihannya dengan serangkaian jumlah epoch. Hasil keluaran dari proses ini dapat membedakan antara fitur yang berpengaruh dan mendominasi dengan fitur tingkat rendah pada citra dan mengklasifikasikannya menggunakan teknik klasifikasi softmax.

\section{E. Confusion Matrix}

Merupakan salah satu metode yang digunakan untuk mengevaluasi kinerja dari algoritma klasifikasi [15]. Tabel 1 merupakan gambaran sedehana untuk mempermudah pemahaman tentang istilah confusion matrix dalam melakukan evaluasi atau pengujian dari model klasifikasi.

Tabel 1. Confusion Matrix

\begin{tabular}{|c|c|c|c|}
\hline \multicolumn{2}{|c|}{} & \multicolumn{2}{c|}{ Kelas Prediksi } \\
\cline { 3 - 4 } \multicolumn{2}{|c}{$\begin{array}{c}\text { Kelas } \\
\text { Sesungguhnya }\end{array}$} & Positif & Negatif \\
\cline { 2 - 4 } & Negatif & TP & FN \\
\hline
\end{tabular}

Tabel 1 di atas menunjukkan beberapa variabel yang berperan untuk proses evaluasi model klasifikasi. Variabel True Negative (TN) merupakan data yang tepat diklasifikasi oleh sistem sebagai nilai negatif atau salah, kemudian variabel True Positive (TP) merupakan data yang tepat diklasifikasi sebagai nilai positif atau benar. Lalu untuk variabel False Positive (FP) merupakan data yang diklasifikasikan tidak tepat 
apabila keluaran berupa positif atau benar kemudian untuk variabel False Negatif(FN) merupakan data yang diklasifikasikan dengan kurang tepat.

Metode confusion matrix ini memiliki beberapa parameter penilaian terhadap kinerja dari model klasifikasi yang dihasilkan adalah :

\section{Precission}

Merupakan parameter penilaian yang menghitung nilai rata-rata precission dari data hasil klasifikasi yaitu jumlah data yang benar antara nilai sebenarnya dengan hasil prediksi model yang dapat dihitung dengan rumus seperti pada persamaan (1) berikut :

Precission $=\frac{\sum_{i}^{n} \frac{T P i}{T P i+F P i}}{n}$

\section{Recall}

Parameter penilaian yang didapat dari jumlah data benar seberapa banyak data yang keluar dalam hasil klasifikasi melalui rumus pada persamaan (2).

Recall $=\frac{\sum_{i}^{n} \frac{T P i}{T P i+F N i}}{n}$

\section{Accuracy}

Parameter penilaian untuk menguji akurasi model dan tingkat confident dalam melakukan klasifikasi terhadap data baru. Untuk mengetahui akurasi suatu model dapat dicari dengan rumus seperti pada persamaan (3) berikut :

Accuracy $=\frac{\sum_{i}^{n} \frac{T P i+T N i}{T P i+F P i+T N i+F N i}}{n}$

\section{METODE PENELITIAN}

Penelitian ini disusun sebagai penelitian eksperimental yakni menerapkan serangkaian tindakan/skenario percobaan dengan melakukan pembelajaran terhadap klasifikasi citra wayang dengan algoritma Convolutional Neural Network dengan beberapa kondisi, baik dalam pemakaian parameter dan perlakuan terhadap data sebelum dilakukan pembelajaran dengan tujuan untuk mengetahui pengaruh dari tingkat akurasi klasifikasi yang dihasilkan menggunakan algoritma CNN. Penelitian ini menggunakan dataset wayang kulit punakawan yang terdiri dari 4 kelas yaitu Semar, Gareng, Petruk dan Bagong.

Dataset diperoleh dengan cara scrapping dari sumber internet yaitu google image. Dalam penelitian ini akan dilakukan beberapa skenario percobaan yang akan menghasilkan beberapa model klasifikasi dengan beberapa perbedaan kondisi terhadap parameter pada CNN yang digunakan untuk melakukan proses training dan perlakuan terhadap data sebelum dilakukan proses training.

Dalam penelitian ini diperlukan beberapa langkah penelitian untuk mendapatkan hasil yang diharapkan seperti ditunjukkan pada gambar 4. Beberapa langkah dalam penelitian ini adalah sebagai berikut :

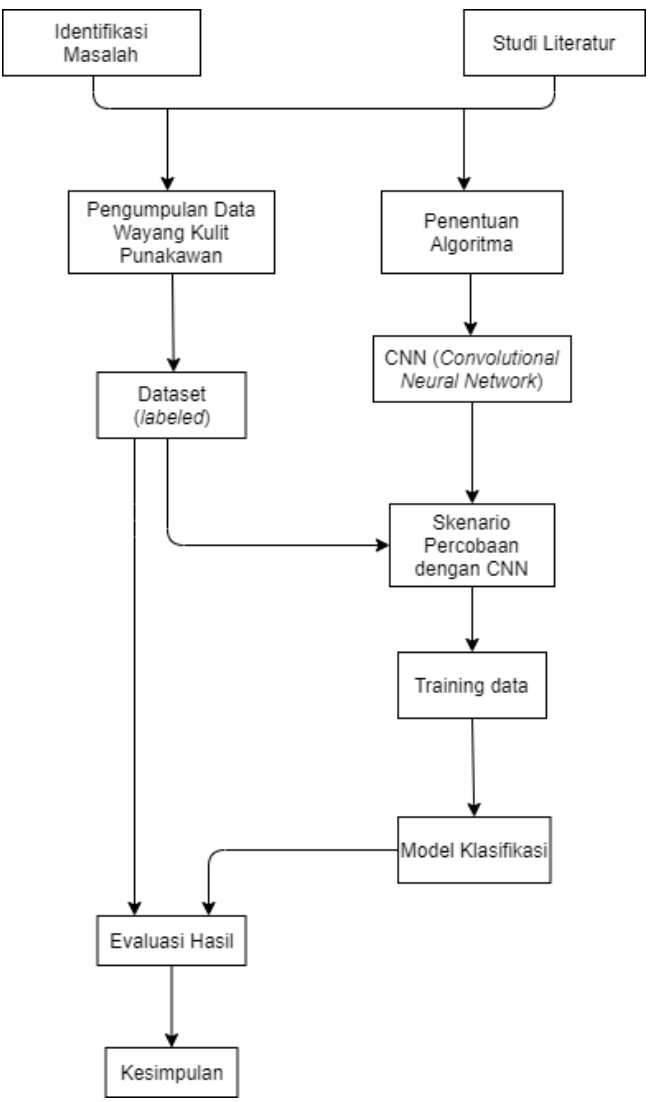

Gambar 4. Alur Penelitian

1. Identifikasi Masalah

Dalam proses identifikasi masalah dilakukan dengan mencari tahu permasalahan yang ada pada objek penelitian dengan membaca beberapa artikel terkait

2. Studi literatur

Dalam studi literatur yang dilakukan adalah dengan mencari dan membaca jurnal serta buku yang relevan dengan permasalahan yang akan diangkat sebagai bahan rujukan dalam memilih metode atau algoritma yang sesuai dan menentukan objek penelitian.

3. Pengumpulan Data Wayang Kulit Punakawan dan Menentukan Algoritma

Setelah membaca beberapa literatur yang relevan, tahap berikutnya adalah proses pengumpulan data berupa wayang kulit dengan tokoh punakawan dari sumber internet dengan metode scrapping menggunakan bahasa pemrograman python dan selenium. Selain itu, setelah membaca penelitianpenelitian terdahulu yang relevan terkait image classification, penulis menentukan untuk menggunakan algoritma Convolutional Neural Network dalam penelitian ini. 


\section{Dataset}

Setelah dilakukan proses scrapping gambar wayang kulit punakawan, langkah berikutnya adalah melakukan beberapa perlakuan terhadap data yang diperoleh. Beberapa perlakuan yang dilakukan seperti memisahkan gambar menjadi 4 kelas sesuai jumlah tokoh wayang punakawan (labeling) dan menyamakan ukuran piksel semua gambar. Dari beberapa perlakuan di atas akan menghasilkan dataset wayang punakawan.

5. CNN (Convolutional Neural Network)

Pada tahap ini telah ditentukan algoritma yang digunakan dalam penelitian ini adalah CNN dengan jumlah 3 lapisan konvolusi (convolution layer), 3 lapisan pooling (pooling layer) dengan aktivasi relu dan 1 lapisan fully connected layer dengan aktivasi softmax, karena jumlah kelas/label lebih dari 2.

6. Skenario percobaan dengan CNN

Pada tahap ini akan ditentukan beberapa skenario percobaan mulai dari perlakuan terhadap pra proses dataset sebelum dilakukan training, rasio dataset terhadap data latih dan data uji dan variasi parameter CNN yang digunakan.

7. Training data

Pada tahap ini akan dilakukan proses pembelajaran atau training terhadap masingmasing skenario menggunakan data training dari dataset wayang kulit punakawan dengan algoritma CNN.

8. Model klasifikasi

Dari tahap training akan menghasilkan model klasifikasi yang akan dilakukan evaluasi model dengan data uji pada proses pengujian, selain itu model ini dapat digunakan untuk mengenali data yang baru.

9. Evaluasi Hasil

Setelah model klasifikasi berhasil dibuat, langkah berikutnya adalah melakukan pengujian atau evaluasi dari model hasil proses pembelajaran. Proses evaluasi menggunakan metode confusion matrix dengan data testing yang telah disediakan. Parameter penilaian dari evaluasi ini adalah aspek accuray, precission, recall dan error rate.

10. Kesimpulan

Setelah melakukan evaluasi terhadap semua model klasifikasi, langkah berikutnya adalah menganalisa dan menyimpulkan hasil evaluasi berdasarkan nilai accuray, precission, recall dan error rate dari masing-masing model untuk mengetahui skenario percobaan terbaik.

\section{HASIL DAN PEMBAHASAN}

Dalam penelitian ini digunakan 400 dataset gambar wayang punakawan (bagong, gareng, petruk dan semar) yang terbagi secara rata menjadi 100 data untuk setiap kelasnya. Dari keseluruhan dataset tersebut nantinya akan dilakukan proses pembagian (split) menjadi data training dan data testing yang akan digunakan dalam percobaan klasifikasi wayang dengan algoritma CNN sebanyak skenario yang telah ditentukan. Data training digunakan untuk proses melatih sistem hingga membentuk suatu model klasifikasi. Model yang terbentuk nantinya yang akan diuji performance nya menggunakan data testing, yaitu data baru yang tidak digunakan dalam proses training dan telah diketahui label/kelasnya. Dari proses testing inilah nantinya akan diketahui keunggulan dan kelemahan dari setiap model yang terbentuk berdasarkan beberapa skenario yang telah ditentukan. Beberapa skenario percobaan pada penelitian ini ditunjukkan pada tabel 2 .

Tabel 2. Skenario Percobaan

\begin{tabular}{|c|c|}
\hline Skenario & Alias \\
\hline Rgb + epoch $50+$ data $70: 30$ & S1 \\
\hline Rgb + augmentation + epoch $50+$ data $70: 30$ & $\mathrm{~S} 2$ \\
\hline Grayscale + epoch $50+$ data $70: 30$ & S3 \\
\hline $\begin{array}{l}\text { Grayscale + augmentation }+ \text { epoch } 50+\text { data } \\
70: 30\end{array}$ & S4 \\
\hline Rgb + epoch $100+$ data $70: 30$ & S5 \\
\hline Rgb + augmentation + epoch $100+$ data $70: 30$ & S6 \\
\hline Grayscale + epoch $100+$ data $70: 30$ & S7 \\
\hline $\begin{array}{l}\text { Grayscale + augmentation + epoch } 100+\text { data } \\
70: 30\end{array}$ & S8 \\
\hline Rgb + epoch $200+$ data $70: 30$ & S9 \\
\hline Rgb + augmentation + epoch $200+$ data $70: 30$ & S10 \\
\hline Grayscale + epoch $200+$ data $70: 30$ & S11 \\
\hline $\begin{array}{l}\text { Grayscale + augmentation + epoch } 200+\text { data } \\
70: 30\end{array}$ & S12 \\
\hline Rgb + epoch $50+$ data $80: 20$ & S13 \\
\hline Rgb + augmentation + epoch $50+$ data $80: 20$ & S14 \\
\hline Grayscale + epoch $50+$ data $80: 20$ & S15 \\
\hline $\begin{array}{l}\text { Grayscale + augmentation }+ \text { epoch } 50+\text { data } \\
80: 20\end{array}$ & S16 \\
\hline Rgb + epoch $100+$ data $80: 20$ & S17 \\
\hline Rgb + augmentation + epoch $100+$ data $80: 20$ & S18 \\
\hline Grayscale + epoch $100+$ data $80: 20$ & S19 \\
\hline $\begin{array}{l}\text { Grayscale + augmentation + epoch } 100+\text { data } \\
80: 20\end{array}$ & S20 \\
\hline $\operatorname{Rgb}+$ epoch $200+$ data $80: 20$ & S21 \\
\hline Rgb + augmentation + epoch $200+$ data $80: 20$ & S22 \\
\hline Grayscale + epoch $200+$ data $80: 20$ & S23 \\
\hline $\begin{array}{l}\text { Grayscale + augmentation + epoch } 200+\text { data } \\
80: 20\end{array}$ & S24 \\
\hline
\end{tabular}

Dari 24 skenario tersebut akan digunakan dalam membentuk model menggunakan dataset yang sama pada proses training. Ukuran citra wayang yang digunakan adalah 180 x 180 piksel sebagai umpan masukan ke dalam arsitektur CNN dengan 3 convolutional layer, 3 max pooling layer dengan aktivasi relu dan 1 fully connected layer dengan aktivasi softmax karena jumlah kelas/label lebih dari 2. Proses 
percobaan ini dilakukan menggunakan library python keras dan dijalankan pada google colab dengan runtime GPU agar proses komputasi lebih cepat. Berikut adalah hasil percobaan dari setiap skenario ditunjukkan pada tabel 3 .

Tabel 3. Hasil Percobaan

\begin{tabular}{|c|c|c|c|c|c|c|c|c|c|c|}
\hline \multirow{2}{*}{ No } & \multirow{2}{*}{$\begin{array}{c}\text { Ske } \\
\text { nario }\end{array}$} & \multirow{2}{*}{$\begin{array}{c}\text { Time/ } \\
\text { step }\end{array}$} & \multicolumn{4}{|c|}{ Training } & \multicolumn{4}{|c|}{ Testing } \\
\hline & & & Loss & Akurasi & Presisi & Recall & Loss & Akurasi & Presisi & Recall \\
\hline 1 & S1 & $2 \mathrm{~s} 95 \mathrm{~ms}$ & 0.0545 & 0.9809 & 0.9092 & 0.8335 & 0.7685 & 0.8045 & 0.9094 & 0.8344 \\
\hline 2 & $\mathrm{~S} 2$ & $3 \mathrm{~s} 179 \mathrm{~ms}$ & 0.1998 & 0.9435 & 0.8757 & 0.7377 & 0.3564 & 0.9102 & 0.8778 & 0.7396 \\
\hline 3 & S3 & $1 \mathrm{~s} 58 \mathrm{~ms}$ & 0.0256 & 0.9936 & 0.9104 & 0.8209 & 1.1209 & 0.7820 & 0.9107 & 0.8220 \\
\hline 4 & $\mathrm{~S} 4$ & $2 \mathrm{~s} 109 \mathrm{~ms}$ & 0.2042 & 0.9314 & 0.8705 & 0.7042 & 0.0461 & 0.9199 & 0.8713 & 0.7063 \\
\hline 5 & S5 & $1 \mathrm{~s} 73 \mathrm{~ms}$ & 0.0267 & 0.9925 & 0.9207 & 0.8804 & 1.9315 & 0.7564 & 0.9207 & 0.8805 \\
\hline 6 & S6 & 2s $487 \mathrm{~ms}$ & 0.0952 & 0.9707 & 0.9219 & 0.8516 & 0.5900 & 0.8878 & 0.9221 & 0.8519 \\
\hline 7 & S7 & $48 \mathrm{~ms}$ & 0.0087 & 0.9987 & 0.9290 & 0.8885 & 1.3667 & 0.8013 & 0.9291 & 0.8888 \\
\hline 8 & $\mathrm{~S} 8$ & $1 \mathrm{~s} 759 \mathrm{~ms}$ & 0.0941 & 0.9638 & 0.9214 & & 0.9468 & & 0.9216 & 396 \\
\hline 9 & S9 & $1 \mathrm{~s} 72 \mathrm{~ms}$ & 0.0126 & 0.9946 & 0.9227 & 0.8820 & 2.6489 & 0.7590 & 0.9226 & 0.8822 \\
\hline 10 & $\mathrm{~S} 10$ & $2 \mathrm{~s} 138 \mathrm{~ms}$ & & & & & & 327 & 0.9392 & 987 \\
\hline 11 & S11 & $1 \mathrm{~s} 47 \mathrm{~ms}$ & 0.0414 & 0.9975 & 0.9314 & 0.9065 & 3.0903 & 0.8269 & 0.9314 & 0.9066 \\
\hline 12 & $\mathrm{~S} 12$ & $1 \mathrm{~s} 83 \mathrm{~ms}$ & 0.0957 & 0.9697 & 0.9443 & 0.9016 & 0.5436 & 0.9087 & 0.9443 & 0.9017 \\
\hline 13 & $\mathrm{~S} 13$ & $1 \mathrm{~s} 73 \mathrm{~ms}$ & 0.0216 & 0.9916 & 0.9217 & 0.8558 & 1.7500 & 0.7375 & 0.9217 & 0.8565 \\
\hline 14 & S14 & $3 \mathrm{~s} 140 \mathrm{~ms}$ & 0.2610 & 0.9073 & 0.8584 & 0.6917 & 0.4502 & 0.8833 & 0.8590 & 0.6937 \\
\hline 15 & $\mathrm{~S} 15$ & $1 \mathrm{~s} 49 \mathrm{~ms}$ & 0.0303 & 0.9906 & 0.9214 & 0.8502 & 3.2073 & 0.7208 & 0.9215 & 0.8510 \\
\hline 16 & S16 & $2 \mathrm{~s} 87 \mathrm{~ms}$ & 0.1481 & 0.9437 & 0.8825 & 0.7438 & 0.1760 & 0.9375 & 0.8833 & 0.7458 \\
\hline 17 & $\mathrm{~S} 17$ & $1 \mathrm{~s} 73 \mathrm{~ms}$ & 0.0622 & 0.9916 & 0.9306 & 0.8911 & 2.8209 & 0.7583 & 0.9306 & 0.8913 \\
\hline 18 & $\mathrm{~S} 18$ & $3 \mathrm{~s} 140 \mathrm{~ms}$ & 0.1324 & 0.9719 & 0.9186 & 0.8441 & 0.5598 & 0.9167 & 0.9188 & 0.8447 \\
\hline 19 & $\mathrm{~S} 19$ & $1 \mathrm{~s} 48 \mathrm{~ms}$ & 0.0173 & 0.9938 & 0.9321 & 0.8979 & 3.7757 & 0.7417 & 0.9321 & 0.8980 \\
\hline 20 & S20 & $2 \mathrm{~s} 92 \mathrm{~ms}$ & 0.0843 & 0.9709 & 0.9301 & 0.8640 & 0.2699 & 0.9708 & 0.9303 & 0.8646 \\
\hline 21 & S21 & $1 \mathrm{~s} 400 \mathrm{~ms}$ & 0.0021 & 0.9990 & 0.9419 & 0.9261 & 7.4633 & 0.7500 & 0.9420 & 0.9261 \\
\hline 22 & $\mathrm{~S} 22$ & $3 \mathrm{~s} 145 \mathrm{~ms}$ & 0.1844 & 0.9458 & 0.9353 & 0.8916 & 0.4085 & 0.9292 & 0.9354 & 0.8917 \\
\hline 23 & $\mathrm{~S} 23$ & $1 \mathrm{~s} 49 \mathrm{~ms}$ & 0.0075 & 0.9990 & 0.9483 & 0.9384 & 9.1000 & 0.7750 & 0.9483 & 0.9384 \\
\hline 24 & S24 & $2 \mathrm{~s} 88 \mathrm{~ms}$ & 0.1353 & 0.9604 & 0.9490 & 0.9124 & 1.0713 & 0.9333 & 0.9490 & 0.9125 \\
\hline
\end{tabular}

Tabel 3 di atas merupakan data-data hasil percobaan terhadap 24 skenario berupa penilaian variabel waktu komputasi, loss, akurasi, presisi, dan recall untuk proses training maupun testing yang akan dibahas lebih detail untuk masing-masing variabel penilaian.

A. Perbandingan waktu komputasi

Dalam penelitian ini dilakukan record terhadap waktu komputasi yang dibutuhkan dalam memproses citra menggunakan algoritma $\mathrm{CNN}$ pada setiap skenario.

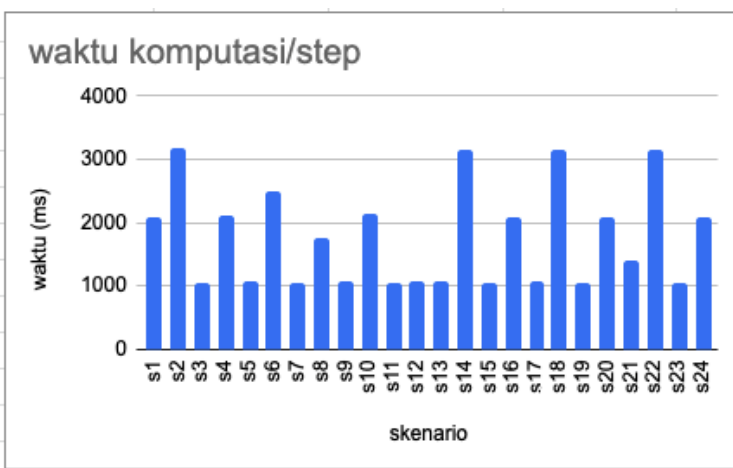

Gambar 5. Grafik waktu komputasi

Grafik yang ditunjukkan pada gambar 5 merepresentasikan rata-rata waktu proses untuk setiap step training dari 24 skenario. Dari grafik tersebut terlihat bahwa skenario yang menggunakan proses augmentation pada preproccessing lebih tinggi dibandingkan yang tidak melalui proses augmentation karena dalam setiap step dibutuhkan waktu lebih untuk melakukan augmentasi citra agar jumlah data yang dilakukan untuk training semakin banyak dengan 
penambahan data hasil augmentasi dari setiap citra. Kemudian dari skenario yang melalui proses augmentasi terlihat bahwa skenario dengan citra RGB waktu komputasi lebih tinggi dibandingkan citra grayscale, karena citra RGB memiliki 3 channel masukan untuk layer konvolusi sedangkan citra grayscale hanya 1 channel saja.

B. Perbandingan training loss dan testing loss

Dalam penelitian ini juga akan dilihat perbandingan nilai loss pada proses training dan juga testing seperti pada gambar 6 berikut ini.

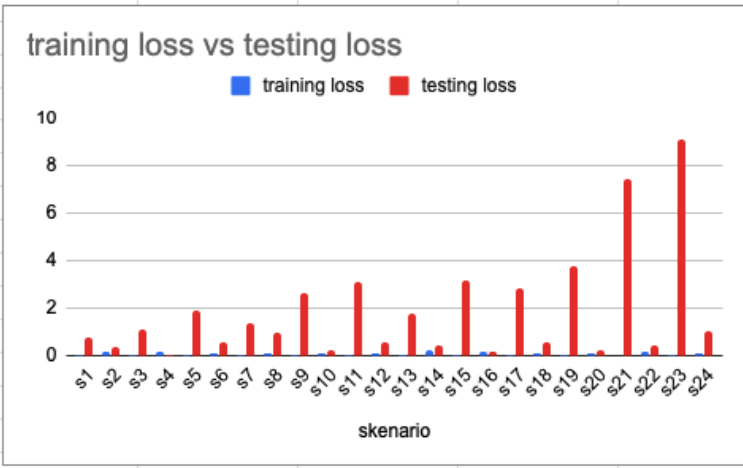

Gambar 6. Grafik loss training dan testing

Pada gambar 6 terlihat bahwa untuk nilai loss pada proses training relatif sama pada setiap skenario, hanya terdapat perbedaan sedikit yaitu skenario dengan proses augmenatiton memiliki nilai training loss sedikit lebih tinggi, karena jumlah citra lebih banyak dengan penambahan posisi citra baru hasil augmentasi. Sedangkan pada testing loss terlihat perbedaan yang sangat mencolok antar skenario yaitu skenario tanpa proses augmentasi cenderung memiliki nilai loss yang lebih tinggi, karena jumlah data yang dilatih lebih sedikit dibandingkan skenario dengan proses augmentasi yang mendapatkan tambahan data citra baru hasil augmentasi dengan berbagai variasi posisi objek dalam citra.

\section{Perbandingan akurasi training dan testing}

Dalam bidang klasifikasi, ukuran akurasi dari suatu model klasifikasi sangat diperhatikan. Nilai akurasi dapat menggambarkan bagus tidaknya suatu model klasifikasi yang nantinya akan digunakan untuk menebak objek/citra baru.

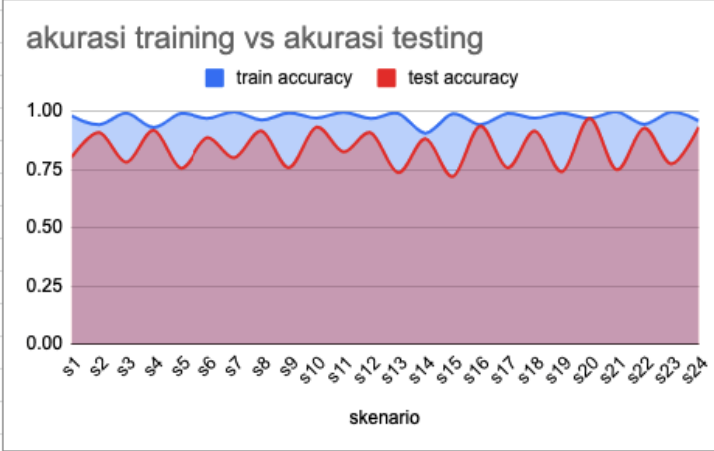

Gambar 7. Grafik akurasi training dan testing

Pada gambar 7 merepresentasikan perbandingan nilai akurasi pada proses training maupun proses testing pada 24 skenario. Dari grafik terlihat bahwa nilai akurasi pada proses training hampir tidak terlihat perbedaan yang signifikan, hanya pada skenario yang menggunakan proses augmentasi akurasi training selalu lebih rendah dibandingkan skenario yang tidak melalui proses augmentasi. Hal tersebut karena jumlah data yang dilatih lebih sedikit, sehingga probability sistem melakukan kesalahan klasifikasi pada proses training lebih kecil.

Akan tetapi kebalikannya, akurasi pada proses testing terlihat jelas perbedaannya dengan ditunjukkannya grafik yang naik turunnya sangat tajam. Pada proses testing, nilai akurasi skenario yang menerapkan augmentasi selalu unggul jauh dibandingkan skenario tanpa augmentasi. Karena model hasil training pada skenario dengan augmentasi lebih baik karena data yang digunakan dalam melatih sistem untuk belajar lebih banyak dengan berbagai variasi posisi citra hasil augmentasi. Sehingga saat dilakukan pengujian dengan data baru, model pada skenario augmentasi lebih dapat mengenal dan mengklasifikasikan citra baru dengan baik dan benar. Selain itu dari skenario-skenario yang menggunakan augmentasi, citra dengan channel grayscale lebih tinggi dibandingkan dengan channel RGB, jumlah epoch yang digunakan dan rasio dataset juga berpengaruh terhadap akurasi yang dihasilkan.

D. Perbandingan presisi training dan testing

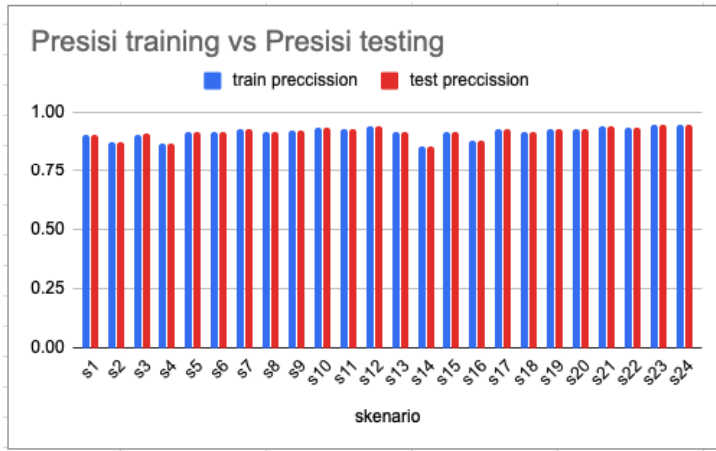

Gambar 8. Grafik presisi training dan testing 
Selain akurasi, terdapat juga variabel penilaian dalam confusion matrix yaitu recall. Berikut adalah grafik recall dari setiap skenario yang ditunjukkan pada gambar 8. Dari grafik tersebut diperlihatkan nilai presisi pada proses training maupun testing yang relatif sama. Untuk setiap skenario baik yang melalui proses augmentasi maupun tidak tidak terlihat perbedaan yang mencolok karena jumlah dataset untuk setiap kelas simetris atau sama jumlahnya. Selain itu skenario dengan jumlah epoch 50 pada skenario yang melalui proses augmentasi selalu memperoleh nilai yang paling rendah dibandingkan skenario yang lain.

\section{E. Perbandingan recall training dan testing}

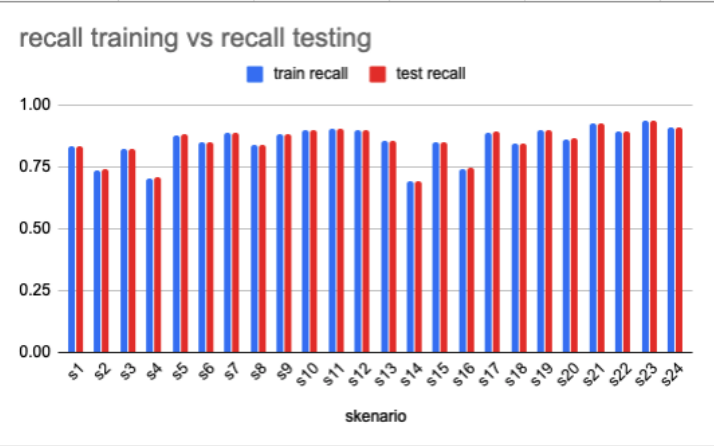

Gambar 9. Grafik recall training dan testing

Pada gambar 9 merepresentasikan grafik perbandingan recall pada proses training maupun testing pada setiap skenario. Dari grafik tersebut terlihat nilai recall pada proses training dan testing memiliki nilai yang relatif sama karena komposisi jumlah data untuk setiap kelas memiliki jumlah yang sama banyak yaitu 100 data untuk 1 kelasnya. Kemudian pada grafik tersebut terlihat bahwa skenario dengan augmentasi dan jumlah epoch yang sedikit yaitu 50 memperoleh nilai recall yang paling kecil karena proses perulangan yang sedikit tidak sebanding dengan data yang ada dari penambahan hasil augmentasi, sehingga nilai maksimal recall belum tercapai karena nilai maksimal epoch telah tercapai.

Dari perbandingan beberapa variabel penilaian yang telah dipaparkan sebelumnya didapatkan nilai akurasi tertinggi khususnya untuk akurasi proses pengujian model adalah sebesar 0.9708 atau $97 \%$ yaitu pada skenario 20. Nilai akurasi dianggap lebih penting dibandingkan nilai presisi dan recall, karena pada penelitian ini jumlah dataset untuk setiap kelas bersifat simetris. Sehingga nilai akurasi lebih mewakili tingkat kualitas dari model klasifikasi. Perlakuan augmentation dan pengubahan channel citra ke grayscale memiliki pengaruh yang signifikan terhadap nilai akurasi yang dihasilkan jika dikombinasikan dengan jumlah epoch yang besar.

Selain itu, rasio pembagian dataset yang digunakan sebagai data training dan testing juga berpengaruh dalam meningkatkan akurasi dengan jumlah nilai epoch yang cukup yaitu 100. Penggunaan nilai epoch yang terlalu besar yaitu 200 dengan jumlah raiso dataset 80:20 tanpa melalui proses augmentation justru menurunkan tingkat akurasi karena minimnya dataset yang digunakan sehingga menimbulkan terjadinya overfitting pada proses training di mana memiliki nilai akurasi yang tinggi pada proses training akan tetapi nilai akurasi sangat rendah pada saat proses pengujian model. Penggunaan epoch yang tinggi akan berpengaruh dalam menghasilkan nilai akurasi yang tinggi jika jumlah data yang digunakan dalam proses training banyak. Pengubahan citra ke channel grayscale dapat meningkatkan kecepatan komputasi pada setiap step/langkahnya.

\section{KESIMPULAN}

Berdasarkan analisa hasil pada percobaan yang telah dilakukan terhadap 24 skenario, dapat disimpulkan bahwa skenario terbaik adalah skenario ke 20 dengan nilai akurasi sebesar $97 \%$, loss/error $2 \%$, presisi $93 \%$ dan recall sebesar $87 \%$. Penggunaan augmentation dan pengubahan channel citra ke grayscale pada preproccessing data training sangat berpengaruh signifikan terhadap nilai akurasi model yang dihasilkan dikombinasikan dengan rasio dataset 80:20 dan epoch 100. Penggunaan nilai epoch juga berpengaruh terhadap akurasi model, semakin tinggi nilai epoch nilai akurasi yang dihasilkan semakin baik jika dataset yang digunakan lebih banyak.

\section{DAFTAR PUSTAKA}

[1] B. Anggoro, "Wayang dan Seni Pertunjukan: Kajian Sejarah Perkembangan Seni Wayang di Tanah Jawa sebagai Seni Pertunjukan dan Dakwah," Sejarah Peradaban Islam, vol. 2, p. 123, 2018.

[2] Pasha, L. Buku Pintar Wayang. Yogyakarta: Bentang Pustaka. 2011.

[3] Effendi, A. Prof. Dr. Ir. Sedyatmo: Intuisi Mencetus daya cipta. Jakarta: Mizan. 2009.

[4] D. R. Indah, "The symbolic meaning of " Punakawan Javanese Wayang ' ( a value imaging study in character education at the character education course in STKIP Bina Insan Mandiri Surabaya )", SELL Journal, eISSN : 2580-8400, pp. 99-106, 2019.

[5] Suseno, F. Wayang dan Panggilan Manusia. Jakarta: Gramedia Pustaka Utama. 1991.

[6] Sandy, B., Siahaan, J.K., Permana, P. dan Muthahir, "Klasifikasi Citra Wayang Dengan Menggunakan Metode K-NN \& GLCM", Prosiding Seminar Nasional Teknologi Informatika, ISBN: 978-602-50006-1-4, pp. 71-77, 2019. 
[7] Islam, K. T., Raj, R. G. and Al-Murad, A., "Performance of SVM, CNN, and ANN with BoW, HOG, and Image Pixels in Face Recognition", 2nd International Conference on Electrical and Electronic Engineering, ICEEE 2017. IEEE, (December), pp. 1-4. doi: 10.1109/CEEE.2017.8412925, 2018.

[8] Cheng, C., Wei, X. and Jian, Z., "Emotion recognition algorithm based on convolution neural network", Proceedings of the 2017 12th International Conference on Intelligent Systems and Knowledge Engineering, ISKE 2017, 2018-January, pp. 1-5. doi: 10.1109/ISKE.2017.8258786, 2017.

[9] Munir, R.. Pengolahan Citra Digital dengan Pendekatan Algoritmik, Jakarta : Informatika. 2004.

[10] S.Y. Iriyanto dan T.M. Zaini, Pengolahan Citra Digital, Lampung: Anugrah Utama Raharja, 2014.

[11] Santoso, B. Data Mining Teknik Pemanfaatan Data untuk Keperluan Bisnis. Yogyakarta: Graha Ilmu. 2007.

[12] Han, J dan Kamber, M., "Data Mining Concept and Technique", Morgan Kaufmann, 2001.

[13] Eka Putra, W. S., "Klasifikasi Citra Menggunakan Convolutional Neural Network (CNN) pada Caltech 101", Jurnal Teknik ITS, 5(1). doi: 10.12962/j23373539.v5i1.15696, 2016

[14] Madenda, S. Pengolahan Citra \& Video Digital. Jakarta: Erlangga 2015. 